\title{
Desempenho de Coelhos em Crescimento Alimentados com Diferentes Níveis de Levedura de Recuperação (Saccharomyces sp.), Seca por Rolo Rotativo ou por Spray-Dry 1 \\ Cláudio Scapinello², Haroldo Garcia de Faria ${ }^{3}$, Antônio Cláudio Furlan², Elias Nunes Martins ${ }^{2}$, Ivan Moreira ${ }^{2}$
}

\begin{abstract}
RESUMO - O objetivo deste trabalho foi estudar a levedura de recuperação (Saccharomyces sp), seca por rolo rotativo (LRRR) ou spray-dry (LRSD), no desempenho de 176 coelhos em crescimento, 88 machos e 88 fêmeas, da raça Nova Zelândia Branco, de 40 a 90 dias de idade. Os animais foram distribuídos em delineamento experimental em blocos cazualizados, com 11 tratamentos (cinco níveis de cada uma das leveduras: 4,0; 8,0;12,0;16,0; e 20,0\%) em substituição gradativa da proteína bruta (PB) do farelo de soja (FS) de uma dieta testemunha, com oito repetições de dois animais por unidade experimental. O peso vivo aos 70 dias de idade, o ganho de peso diário e o consumo diário de dieta de 40 a 70 dias de idade diminuíram linearmente, à medida que se elevou o nível de LRRR nas dietas. No período total, de 40-90 dias de idade, o consumo diário dos animais que receberam ração com LRRR diminuiu linearmente, com melhora linear na conversão alimentar. A inclusão de LRSD nas dietas não influenciou o desempenho dos coelhos nos níveis estudados. A inclusão de 16 e 20\% de LRRR e LRSD na dieta acarretou em elevada mortalidade dos animais, com quadro de enterite aguda, especialmente no período de 40 a 70 dias de idade. Os dados indicam que a LRSD substituiu mais eficientemente a PB do FS que a LRRR, entretanto, devido à elevada mortalidade, recomenda-se não usar mais que $15 \%$ de inclusão das leveduras estudadas.
\end{abstract}

Palavras-chave: coelhos, desempenho, levedura de recuperação

\section{Performance of Growing Rabbits Fed with Different Levels of Restorative Yeast (Saccharomyces sp), Dried by Rotative Roller or by Spray-Dry}

\begin{abstract}
The objective of this work was to study the restorative yeast (Saccharomyces sp) dried by rotative roller (RYRR) or by spray-dry (RYSD), on the performance of 176 growing rabbits, 88 males and 88 females, white New Zealand breed, from 40 to 90 days of age.The animals were distributed in a randomized complete block design, with 11 treatments (five levels of each one yeast: $4.0,8.0$ 12.016 .0 , and 20,0\%) in gradually replacement of soybean meal (SM) crude protein (CP) of a control diet, with eight replicates and two animals per experimental unit. The live weight at 70 days of age, daily weight gain and the daily diet intake from 40 to 70 days of age decreased linearly as the RYRR level increased in the diet. In the total period, from 40 to 90 days of age, the daily intake of the animals that received RYRR decreased linearly, with linear improvement in the feed:gain ratio. The inclusion of RYSD on the diets did not influence the performance of rabbits in the studied levels. The inclusion of 16 and $20 \%$ of RYRR and RYSD in the diet caused a higher mortality of animals, with acute enterite, especially during the period from 40 to 70 days of age. The data showed that RYSD replaced more efficiently the CP of SM than RYRR. However, due to the high mortality, the recommendation is not to use more than $15 \%$ of inclusion of the studied yeast.
\end{abstract}

Key Words: rabbit, performance, restorative yeast

\section{Introdução}

A principal fonte de proteína de dietas para coelhos é o farelo de soja, porém outros subprodutos da agroindústria devem ser pesquisados na tentativa de viabilizar sua utilização como componente de dietas para animais.

O Brasil é o maior produtor de álcool, e os resíduos obtidos no processamento da cana-de-açúcar podem ser de grande importância na alimentação humana e animal, com a utilização direta na alimen- tação ou por meio do emprego como fertilizantes. Segundo LIMA (1983), a levedura obtida na produção de álcool (Saccharomyces cerevisiae) é um produto que pode ter significativa importância na alimentação animal.

As leveduras são consideradas importantes suplementos protéicos dos cereais, devido a seu alto conteúdo de lisina; portanto, quando utilizados com alimentos ricos em aminoácidos sulfurados, permitem adequadas formulações de dietas (HANSSEN, 1980).

Em virtude de sua riqueza de nutrientes, as leve-

\footnotetext{
${ }_{1}^{1}$ Projeto financiado pelo CNPq.

2 Professor do Departamento de Zootecnia, UEM- Av. Colombo 5790 - 87020-900 - Maringá, PR.

${ }^{3}$ Zootecnista, Biotério Central, UEM.
} 
duras apresentam três opções de uso na alimentação de monogástricos: fonte de proteína, fonte de fatores desconhecidos de crescimento e fonte de vitaminas (MOREIRA, 1984).

Existem diferentes métodos industriais de secagem da levedura para sua incorporação em rações. $\mathrm{O}$ mais conhecido e utilizado atualmente nas usinas é o de rolo rotativo; neste método, o processo básico consiste na centrifugação da vinhaça após destilação do vinho para possibilitar a separação da levedura da parte solúvel. A seguir, a levedura passa por processo de secagem, em que a temperatura nos rolos varia de 110 a $128^{\circ} \mathrm{C}$, sendo obtida película de concentrado protéico com teor de proteína bruta de 18 a $32 \%$ (SALGADO, 1976).

No método de secagem por spray-dry, o creme de levedo termolizado é pulverizado no topo do corpo do equipamento e recebe ar aquecido de 200 a $220^{\circ} \mathrm{C}$. $\mathrm{O}$ ar e o levedo atravessam o corpo do secador e saem pela parte inferior, em direção a um ciclone onde ocorre a separação entre o ar e o levedo seco, que é ensacado logo em seguida (informações colhidas na usina produtora - Destilaria Vale do Ivaí).

Embora poucas pesquisas sobre a utilização da levedura de recuperação (Saccharomyces sp.) tenham sido desenvolvidas com coelhos (FAZANO et al., 1989; CARREGAL e FONSECA., 1990; e CARREGAL et al., 1990), vários trabalhos foram realizados com outras espécies, entre elas suínos, indicando sua viabilidade da utilização (MIYADA e LAVORENTI, 1979., 1979; MOREIRA., 1984; BERTO., 1985; NUNES., 1988; MIYADA et al., 1992; LANDELL et al., 1994; e MOREIRA et al., 1994). Por outro lado, na literatura consultada, apenas SCAPINELLO et al. (1996) informam sobre o uso de levedura seca por spray-dry na alimentação de coelhos.

Como a tecnologia spray-dry tende a se expandir e, portanto, maior volume de levedura produzida por este meio estará disponível no mercado, sendo importante aos nutricionistas conhecerem o seu potencial de utilização na alimentação animal.

Diante do exposto, o objetivo deste trabalho foi avaliar a inclusão da levedura de recuperação (Saccharomyces $s p$.), seca por rolo rotativo ou por spray-dry, em substituição gradativa da proteína bruta do farelo de soja, em dietas para coelhos em crescimento.

\section{Material e Métodos}

O experimento foi conduzido no Setor de Cunicultura da Fazenda Experimental de Iguatemi, da Universidade Estadual de Maringá, no período de março a abril de 1996.

Foram utilizados 176 coelhos da raça Nova Zelândia Branco, 88 machos e 88 fêmeas, com 40 dias de idade, alojados em gaiolas de arame galvanizado, providas de bebedouros automático e comedouros semi-automático de chapa galvanizada, localizados em galpão de alvenaria, com cobertura de telha francesa, pé direito de 3,0 metros, piso de alvenaria, paredes laterais de $50 \mathrm{~cm}$ em alvenaria e o restante em tela e cortina de plástico para controle de ventos. A temperatura média registrada no período experimental foi de $21^{\circ} \mathrm{C}$, sendo que a máxima registrada foi de $22^{\circ} \mathrm{C}$ e a mínima, de $19^{\circ} \mathrm{C}$.

Os animais foram distribuídos em delineamento experimental em blocos casualizados com 11 tratamentos e oito repetições de dois animais por unidade experimental. Foi formulada dieta referência de acordo com as recomendações do AEC (1987) para coelhos em crescimento, sendo que, para as demais dietas, a proteína bruta do farelo de soja foi sendo substituída gradativamente com inclusão de levedura de recuperação $(4,8,12,16$ e 20\%), seca em rolo rotativo ou por spray-dry.

Para balanceamento da energia digestível das dietas contendo levedura, foram utilizados os valores de energia digestível obtido no ensaio de digestibilidade de $3248 \mathrm{kcal} / \mathrm{kg}$ para LRRR e de $3859 \mathrm{kcal} / \mathrm{kg}$ para LRSD. As composições percentual e química e valor energético e o custo por quilo das dietas experimentais encontram-se na Tabela 1.

Após a mistura, as dietas foram peletizadas a seco, sendo fornecidas dietas e água à vontade.

Os coelhos foram pesados no início do experimento com 40 dias de idade, aos 70 dias de idade, e no final do experimento, com 90 dias de idade. As dietas fornecidas e as sobras também foram pesadas a cada pesagem dos animais.

O abate dos animais, no final do experimento, foi realizado conforme descrição feita por SCAPINELLO (1993).

O modelo estatístico para análise das características de desempenho e carcaça e econômicas foi:

$$
\begin{gathered}
\mathrm{Y}_{i j k l m}=\mu+\mathrm{F}_{i}+\mathrm{B}_{l}+\mathrm{b}_{i l}\left(\mathrm{~N}_{i j}+\mathrm{N}_{l}\right)+\mathrm{b}_{i 2}\left(\mathrm{~N}_{i j}-\mathrm{N}_{l}\right)^{2}+ \\
\mathrm{S}_{k}+\mathrm{e}_{i j k l m}
\end{gathered}
$$

em que

$\mathrm{Y}_{i j k l m}=$ valor observado das variáveis estudada, relativo ao indivíduo $m$, de sexo $k$, de bloco $l$ que recebeu a fonte de proteína $i$, com nível de inclusão $j$;

$\mu=$ constante geral;

$\mathrm{F}_{i}=$ efeito da fonte de proteína $i$, sendo $i=1,2 \mathrm{e}$ 
3 ( 1 = farelo de soja $2=$ LRRR e $3=$ LRSD);

$\mathrm{B}_{l}=$ efeito do bloco $l$, sendo $l=1$ e 2 ;

$\mathrm{b}_{i 1}=$ coeficiente linear de regressão da variável

$\mathrm{Y}$, em função dos níveis de inclusão da fonte $i$, para todo i maior que 1 ;

$\mathrm{b}_{i 2}=$ coeficiente quadrático de regressão da variável $\mathrm{Y}$, em função dos níveis de inclusão da fonte $i$, para todo $i$ maior que 1 ;

$\mathrm{N}_{i j}$ = efeito do nível $j$ de inclusão de levedura da fonte $i$; para todo $i$ maior que 1 ;

$\mathrm{N}_{l}=$ média dos níveis de inclusão de levedura da fonte $i$, para todo $i$ maior que 1 ;

$\mathrm{S}_{k}=$ efeito do sexo $k$, em que $k=1$ e 2 ; e

$\mathrm{e}_{i j k l m}=$ erro aleatório associado a cada observação.

As médias das características estudadas, obtidas com o uso da dieta testemunha, foram comparadas às obtidas com as dietas contendo diferentes níveis de inclusão de levedura por meio do teste Dunnett e teste $\mathrm{t}(\mathrm{P}<0,05)$. $\mathrm{O}$ número de animais mortos dos tratamentos contendo diferentes níveis de levedura foi comparado com a dieta testemunha por meio do teste Fischer $(\mathrm{P}<0,06)$.

Para comparação das três fontes de proteína das rações, foi utilizado o teste Tukey $(\mathrm{P}<0,05)$.

\section{Resultados e Discussão}

As médias de peso vivo aos 70 dias de idade, ganho de peso diário, consumo de ração diário e conversão alimentar, no período de 40-70 dias de idade, de acordo com os diferentes níveis de inclusão de LRRR e LRSD, em substituição à proteína bruta do farelo de soja, são mostradas na Tabela 2 .

Entre características avaliadas, no período de 4070 dias de idade, aplicando-se o teste Dunnett, apenas o consumo diário dos animais que recebam dieta com $20 \%$ de LRRR, substituindo totalmente a proteína bruta do farelo de soja, foi menor $(\mathrm{P}<0,05)$ que o de animais alimentados com dieta testemunha, enquanto, aplicando-se o teste $t$, alem destes, os animais que receberam a dieta com $16 \%$ de LRRR, substituindo $80 \%$ da proteína bruta do farelo de soja, também apresentaram menor consumo diário $(\mathrm{P}<0,05)$ em relação à testemunha.

Comparando-se as fontes de proteínas avaliadas pelo teste Tukey, apenas o consumo diário de ração dos animais que receberam ração com LRRR foi menor $(\mathrm{P}<0,05)$ do que os que receberam farelo de soja e LRSD.

A análise de regressão demonstrou que a substituição gradativa da proteína bruta do farelo de soja pela LRRR prejudicou linearmente $(\mathrm{P}<0,05)$ o peso vivo aos
70 dias, o ganho de peso diário e o consumo de ração diário no período de 40 a 70 dias de idade. Os dados mostram que a queda linear no ganho de peso dos animais que receberam dietas com níveis crescentes de LRRR deve-se à redução no consumo de ração, uma vez que a conversão alimentar não foi influenciada.

Estes resultados diferem dos encontrados por CARREGAL e FONSECA (1990), em que os coelhos alimentados com ração contendo $6,22 \%$ de inclusão de levedura na dieta obtiveram melhor resultado para ganho de peso e conversão alimentar em relação aos demais níveis de inclusão de levedura avaliados até $24,88 \%$. Esses autores constataram também que a dieta contendo somente farelo de soja proporcionou consumo inferior à dieta com levedura seca em níveis crescentes.

Por outro lado, os resultados do presente trabalho estão de acordo com os encontrados por MIYADA et al. (1992), que, trabalhando com leitões em fase de recria, verificaram redução no consumo e, como conseqüência, redução no ganho de peso dos animais, quando a levedura foi incluída em níveis acima de 13,8\%.

A redução no ganho de peso observado no presente trabalho pode ser atribuído a efeito negativo na palatabilidade das dietas. Essa constatação tem como base os trabalhos realizados por MIYADA et al. (1992), que trabalhando com suínos, atribuiu os menores ganhos a efeito negativo na palatabilidade das dietas contendo levedura. TEGBE e ZIMMERMAN (1977), trabalhando com levedura para suínos, afirmam que a levedura proporcionou dietas de consistência mais pegajosa na boca dos animais, dificultando sua ingestão.

Quanto à conversão alimentar, MOREIRA (1984) também não observou diferença significativa em suínos nas fases de crescimento e acabamento recebendo rações com níveis crescentes de inclusão de levedura seca. Contudo, BRENNE et al. (1974), MIYADA e LAVORENTI (1979) e MIYADA (1987) observaram que, com o aumento dos níveis de levedura, ocorreu efeito linear depressivo sobre a conversão alimentar. Este resultado foi atribuído a maior consumo alimentar pelos animais, de modo a balancear seu consumo energético, tendo em vista que a levedura seca tem menor teor energético que o farelo de soja.

O uso de LRSD, em substituição gradativa a proteína do farelo de soja, não influenciou as características estudadas até os 70 dias de idade.

SCAPINELLO et al. (1996), avaliando os efeitos da substituição gradativa da proteína bruta do farelo de soja pela LRSD, até $100 \%$ para coelhos em crescimento, no período de 40-70 dias, constataram não haver efeito no desempenho dos coelhos nos níveis estudados. 
338 Rev. bras. zootec.

Tabela 2 - Peso vivo aos 70 dias, ganho de peso diário, consumo de ração diário e conversão alimentar de coelhos de 40 a 70 dias, de acordo com os diferentes níveis de substituição da proteína bruta do farelo de soja pela proteína bruta da levedura de recuperação, seca por rolo rotativo (LRRR) ou spray-dry (LRSD)

Table 2 - $\quad$ Live weight at 70 days, daily weight gain, daily diet intake and feed:gain ratio of rabbits from 40 to 70 days of age according to the different levels of soybean meal crude protein substitution by restorative yeast, crude totein dried rotative roller (RYRR) or by spray-dry(RYSD)

\begin{tabular}{|c|c|c|c|c|c|c|c|c|c|c|c|c|c|c|}
\hline \multirow[b]{3}{*}{$\begin{array}{l}\text { Sexo }^{1} \\
\text { Sex }\end{array}$} & \multirow[b]{3}{*}{$\begin{array}{c}\text { Test. } \\
\text { Control }\end{array}$} & \multirow{2}{*}{\multicolumn{5}{|c|}{$\begin{array}{l}\text { LRRR(\%) } \\
\text { RYRR }\end{array}$}} & \multicolumn{7}{|c|}{ LRSD(\%) } & \multirow{3}{*}{ Média } \\
\hline & & & & & & & \multirow[b]{2}{*}{$\begin{array}{l}\text { Média } \\
\text { Mean }\end{array}$} & \multicolumn{5}{|c|}{ RYSD } & \multirow[b]{2}{*}{$\begin{array}{l}\text { Média } \\
\text { Mean }\end{array}$} & \\
\hline & & 4 & 8 & 12 & 16 & 20 & & 4 & 8 & 12 & 16 & 20 & & \\
\hline \multicolumn{15}{|c|}{$\begin{array}{l}\text { Peso vivo (g) } \\
\text { Live weight }\end{array}$} \\
\hline Macho & 2156 & 2140 & 2208 & 2144 & 1993 & 1935 & 2081 & 2171 & 2224 & 2162 & 2112 & 2146 & 2164 & $2126 a$ \\
\hline Fêmea & 2238 & 2171 & 2152 & 2144 & 2110 & 2030 & 2118 & 2102 & 2097 & 2127 & 2127 & 2232 & 2243 & $2150 a$ \\
\hline Média & 2197 & 2156 & 2177 & 2144 & 2051 & 1983 & 2100 & 2136 & 2160 & 2144 & 2171 & 2197 & $2158 \mathrm{~A}$ & 2138 \\
\hline
\end{tabular}

Mean

Ganho de peso diário $(\mathrm{g})$

\begin{tabular}{|c|c|c|c|c|c|c|c|c|c|c|c|c|c|c|}
\hline \multicolumn{15}{|c|}{ Daily weight gain } \\
\hline Macho & 36 & 36 & 38 & 36 & 31 & 29 & 34 & 36 & 38 & 37 & 35 & 35 & 36 & $35 \mathrm{a}$ \\
\hline Fêmea & 39 & 37 & 36 & 36 & 35 & 32 & 35 & 34 & 34 & 35 & 38 & 39 & 36 & $36 a$ \\
\hline Média ${ }^{3}$ & $37 \mathrm{~A}$ & 36 & 37 & 36 & 33 & 30 & $34 \mathrm{~A}$ & 35 & 36 & 36 & 37 & 37 & $36 \mathrm{~A}$ & 36 \\
\hline \multicolumn{15}{|c|}{$\begin{array}{c}\text { Consumo de ração diário }(\mathrm{g}) \\
\text { Daily feed intake }\end{array}$} \\
\hline Macho & 125 & 121 & 115 & 129 & 108 & 97 & 114 & 110 & 134 & 135 & 121 & 128 & 125 & $120 \mathrm{a}$ \\
\hline Fêmea & 126 & 121 & 113 & 123 & 108 & 112 & 115 & 121 & 122 & 118 & 127 & 126 & 122 & $120 \mathrm{a}$ \\
\hline Média 4 & $126 \mathrm{~A}$ & 121 & 114 & 126 & $108^{*}$ & $104 *+$ & $115 \mathrm{~B}$ & 115 & 128 & 126 & 124 & 127 & $124 \mathrm{~A}$ & 120 \\
\hline
\end{tabular}

Mean

\begin{tabular}{|c|c|c|c|c|c|c|c|c|c|c|c|c|c|c|}
\hline \multicolumn{15}{|c|}{ Feed:gain ratio } \\
\hline Macho & 3,48 & 3,43 & 3,04 & 3,62 & 3,57 & 3,51 & 3,45 & 3,00 & 3,51 & 3,70 & 3,58 & 3,59 & 3,47 & $3,46 a$ \\
\hline Fêmea & 3,28 & 3,33 & 3,13 & 3,49 & 3,15 & 3,54 & 3,33 & 3,54 & 3,66 & 3,42 & 3,29 & 3,27 & 3,45 & $3,37 \mathrm{a}$ \\
\hline Média & $3,38 \mathrm{~A}$ & 3,38 & 3,09 & 3,56 & 3,36 & 3,52 & $3,39 \mathrm{~A}$ & 3,27 & 3,58 & 3,56 & 3,44 & 3,43 & $3,46 \mathrm{~A}$ & 3,42 \\
\hline
\end{tabular}

+ Difere da testemunha pelo teste Dunnett $(\mathrm{P}<0,05)$.

+ Differ from control by Dunnett test $(P<.05)$.

* Difere da testemunha pelo teste $\mathrm{T}(\mathrm{P}<0,05)$.

* Differ from control by $T$ test $(P<.05)$.

${ }^{1}$ Macho (Male), fêmea (female).

2 Efeito linear para níveis de LRRR (Linear effect for RYRR levels) $\left(R^{2}=0,82\right)(\hat{Y}=2242,1688-11,65348 X)$.

2 Efeito linear para níveis de LRRR (Linear effect for RYRR levels) $\left(R^{2}=0,86\right)(\hat{Y}=39,114343-0,402736 X)$.

3 Efeito linear para níveis de LRRR (Linear effect for RYRR levels) $\left(R^{2}=0,50\right)(\hat{Y}=126,77004-1,01512 X)$.

Médias, na linha, seguidas de letra diferentes são diferentes $(P<0,05)$ pelo teste Tukey.

Means, within a row, followed by different letters are different $(P<.05)$ by Tukey test .

Médias, na coluna, seguidas de letra diferentes são diferentes $(P<0,05)$ pelo teste $F$.

Means, within a column, followed by different letters are different $(P<.05)$ by $F$ test.

As médias de peso vivo aos 90 dias de idade, ganho de peso diário, consumo diário de ração e conversão alimentar, no período de 40-90 dias de idade, de acordo com os níveis de inclusão de LRRR e LRSD, em substituição à proteína bruta do farelo de soja, são mostradas na Tabela 3.

Aplicando-se o teste Dunnett, apenas o consumo diário de ração dos animais que receberam dieta com 16 e $20 \%$ de LRRR, substituindo 80 e $100 \%$ da proteína bruta do farelo de soja, foi menor $(\mathrm{P}<0,05)$ que o de animais que receberam a dieta testemunha.
Contudo, aplicando-se o teste t, além destes, a conversão alimentar dos animais que receberam 16\% de LRRR e $12 \%$ LRSD, substituindo, respectivamente, 80 e $60 \%$ da proteína bruta do farelo de soja, foi diferente $(\mathrm{P}<0,05)$, quando comparada à de animais que receberam dieta testemunha.

Comparando as fontes de proteínas avaliadas, pelo teste Tukey, apenas o peso vivo aos 90 dias de idade e o consumo de ração diário dos animais que receberam ração com LRRR foram menores $(\mathrm{P}<0,05)$ em relação à dieta com farelo de soja. 
SCAPINELLO et al.

Tabela 3 - Peso vivo aos 90 dias, ganho de peso diário, consumo de ração diário e conversão alimentar de coelhos de 40 a 90 dias, de acordo com os diferentes níveis de substituição da proteína bruta do farelo de soja pela proteína bruta da levedura de recuperação seca por rolo rotativo (LRRR) ou spray-dry (LRSD)

Table 3 - $\quad$ Live weight at 90 days, daily weight gain, daily diet intake and feed: gain ratio of rabbits from 40 to 90 days of age according to the different levels of soybean meal crude protein substitution by restorative yeast dried rotative roller (RYRR) or spray-dry (RYSD)

\begin{tabular}{|c|c|c|c|c|c|c|c|c|c|c|c|c|c|c|}
\hline \multirow[b]{2}{*}{$\begin{array}{l}\operatorname{Sexo}^{1} \\
\operatorname{Sex}\end{array}$} & \multirow[b]{2}{*}{$\begin{array}{l}\text { Test. } \\
\text { Control }\end{array}$} & \multicolumn{5}{|c|}{$\begin{array}{l}\text { LRRR (\%) } \\
\quad R Y R R\end{array}$} & \multirow[b]{2}{*}{$\begin{array}{l}\text { Média } \\
\text { Mean }\end{array}$} & \multicolumn{5}{|c|}{$\begin{array}{l}\text { LRSD }(\%) \\
\quad R Y S D\end{array}$} & \multirow[b]{2}{*}{$\begin{array}{l}\text { Média } \\
\text { Mean }\end{array}$} & \multirow{2}{*}{$\begin{array}{l}\text { Média } \\
\text { geral } \\
\text { General } \\
\text { mean }\end{array}$} \\
\hline & & 4 & 8 & 12 & 16 & 20 & & 4 & 8 & 12 & 16 & 20 & & \\
\hline \multicolumn{15}{|c|}{$\begin{array}{l}\text { Peso vivo }(\mathrm{g}) \\
\text { Live weight }\end{array}$} \\
\hline Macho & 2777 & 2706 & 2692 & 2615 & 2664 & 2663 & 2660 & 2866 & 2812 & 2648 & 2720 & 2645 & 2473 & $2707 \mathrm{a}$ \\
\hline Fêmea & 2972 & 2897 & 2770 & 2720 & 2774 & 2735 & 2773 & 2773 & 2802 & 2779 & 2929 & 2879 & 2822 & $2821 b$ \\
\hline Média & 2875 & 2802 & 2731 & 2668 & 2719 & 2684 & 2717 & 2820 & 2807 & 2714 & 2824 & 2762 & $2782 \mathrm{~A}$ & 2764 \\
\hline \multicolumn{15}{|c|}{$\begin{array}{c}\text { Ganho de peso diário (g) } \\
\text { Daily weight gain }\end{array}$} \\
\hline Macho & 34 & 33 & 32 & 31 & 32 & 31 & 32 & 36 & 35 & 32 & 33 & 31 & 33 & $33 a$ \\
\hline Fêmea & 38 & 37 & 34 & 33 & 34 & 33 & 34 & 34 & 34 & 34 & 38 & 36 & 35 & $35 b$ \\
\hline Média & $36 \mathrm{~A}$ & 35 & 33 & 32 & 33 & 32 & $33 \mathrm{~A}$ & 35 & 35 & 33 & 35 & 34 & $34 \mathrm{~A}$ & 34 \\
\hline \multicolumn{15}{|c|}{$\begin{array}{c}\text { Consumo de ração diário }(\mathrm{g}) \\
\text { Daily diet intake }\end{array}$} \\
\hline Macho & 141 & 137 & 132 & 138 & 113 & 118 & 128 & 131 & 148 & 144 & 137 & 135 & 139 & $134 a$ \\
\hline Fêmea & 140 & 141 & 131 & 133 & 123 & 124 & 130 & 137 & 140 & 137 & 141 & 138 & 138 & $135 \mathrm{a}$ \\
\hline Média & $140 \mathrm{~A}$ & 139 & 131 & 136 & $118^{*+}$ & $121 *+$ & $129 \mathrm{~B}$ & 134 & 144 & 141 & 139 & 137 & $139 \mathrm{~A}$ & 135 \\
\hline \multicolumn{15}{|c|}{$\begin{array}{c}\text { Conversão alimentar } \\
\text { Feed:gain ratio }\end{array}$} \\
\hline Macho & 4,41 & 4,22 & 4,06 & 4,51 & 3,35 & 3,79 & 4,00 & 3,86 & 4,28 & 4,61 & 4,20 & 4,31 & 4,21 & $4,09 \mathrm{a}$ \\
\hline Fêmea & 3,71 & 3,88 & 3,86 & 4,08 & 3,69 & 3,74 & 3,85 & 4,05 & 4,05 & 4,03 & 3,81 & 3,86 & 3,98 & $3,89 b$ \\
\hline $\begin{array}{l}\text { Média } \\
\text { Mean }\end{array}$ & $3,93 \mathrm{~A}$ & 4,05 & 3,96 & 4,29 & $3,47^{*}$ & 3,77 & 3,92 & 3,86 & 4,16 & $4,32 *$ & 4,00 & 4,09 & $4,09 \mathrm{~A}$ & 3,99 \\
\hline
\end{tabular}

A análise de regressão demonstrou que a substituição gradativa da proteína bruta do farelo de soja pela LRRR prejudicou linearmente $(\mathrm{P}<0,05)$ o consumo de ração diário e melhorou linearmente $(\mathrm{P}<0,05)$ a conversão alimentar.

Diferentes resultados foram obtidos por CARREGAL e FONSECA (1990), que, trabalhando com coelhos de 35 a 70 dias, encontraram melhor ganho de peso diário, consumo de ração e conversão alimentar com dietas que continham $6,22 \%$ de inclusão de levedura na dieta.

TEGBE e ZIMMERMAN (1977), MIYADA e LAVORENTI (1979), FORSTAD et al. (1980), HANSSEN e FORSTAD (1980) e LIMA (1983), trabalhando com suínos, também não observaram efeito significativo sobre o ganho de peso diário nas fases de crescimento e acabamento, quando a levedura foi adicionada na dieta.

Os resultados obtidos com a inclusão de LRRR são semelhantes aos obtidos por MIYADA et al. (1992), que constataram menor consumo e melhora na conversão alimentar, com níveis de inclusão acima de $13,8 \%$ para leitões em recria.

A inclusão de LRSD em substituição gradativa da proteína bruta do farelo de soja não influiu nas características estudadas no período de 40-90 dias.

SCAPINELLO et al. (1996), trabalhando com coelhos em crescimento no período de 40-80 dias, constataram melhora linear na conversão alimentar com a substituição da proteína bruta do farelo de soja pela proteína bruta da LRSD em níveis crescente até 100\%.

Os dados de peso e rendimento de carcaça de coelhos abatidos aos 90 dias são mostrados na Tabela 4 .

Aplicando-se o teste Dunnett, não se verificaram diferenças entre os tratamentos que receberam inclusão de LRRR e LRSD e a dieta testemunha.

Comparando-se as fontes de proteínas avaliadas, pelo teste Tukey, apenas o peso da carcaça dos animais 
340 Rev. bras. zootec.

que receberam dieta contendo LRRR foi menor $(\mathrm{P}<0,05)$ que o de animais que receberam farelo de soja.

A análise de regressão demonstrou não haver diferenças no peso de carcaça e rendimento de carcaça, com a substituição gradativa da proteína bruta do farelo de soja pela proteína tanto da LRRR como da LRSD.

O número de mortes de coelhos nos períodos estudados, de acordo com os níveis de inclusão de LRRR e LRSD nas dietas, em substituição a proteína bruta do farelo de soja, encontram-se na Tabela 5.

Os resultados mostram que as rações com $16 \mathrm{e}$ 20\% de inclusão, tanto de LRRR como de LRSD, substituindo, respectivamente, 80 e $100 \%$ da proteína bruta do farelo de soja, provocaram elevadas taxas de mortalidade, especialmente no período de 40 a 70 dias de idade. Entretanto, pelo teste Fischer, apenas o número de animais mortos no tratamento em que a levedura de recuperação LRRR substituiu totalmente a proteína bruta do farelo de soja foi maior $(\mathrm{P}<0,06)$ em relação aos animais que receberam a ração testemunha.

A elevada mortalidade, possivelmente, pode estar relacionada com a origem da fonte de proteína, uma vez que alguns fatores, como substrato, grau de aeração do meio, métodos de fermentação, idade das células e nível de lavagem para eliminação de impu- rezas, podem implicar na qualidade do subproduto estudado, sendo necessário, portanto, acompanhamento constante da qualidade nutricional das leveduras comercializadas.

O custo da ração consumida por quilo de ganho de peso de coelhos, nos períodos de 40-70 dias de idade e 40-90 dias de idade, de acordo com diferentes níveis de inclusão de LRRR e LRSD nas rações, em substituição à proteína bruta do farelo de soja, são mostrados na Tabela 6.

Aplicando-se o teste Dunnet, no período de 40-70 dias de idade, o custo por quilo de peso vivo dos animais que receberam dietas com 16 e $20 \%$ de LRRR substituindo 80 e $100 \%$ da proteína bruta do farelo de soja, foi menor $(\mathrm{P}<0,05)$ em relação à dieta testemunha. No período de 40-90 dias de idade, tanto o teste Dunnett como o teste $\mathrm{t}$ acusaram diferença no custo na ração substituindo $80 \%$ da proteína bruta do farelo de soja.

Comparando as fontes de proteína avaliadas pelo teste Tukey, não houve diferença $(\mathrm{P}>0,05)$ entre as fontes de proteína.

A análise de regressão demonstrou que a substituição gradativa da proteína bruta do farelo de soja pela LRRR apresentou efeito linear $(\mathrm{P}<0,05)$ no custo por quilo de peso vivo em ambos os períodos, 40-70 dias e 40-90 dias.

Tabela 4 - Peso da carcaça e rendimento de carcaçade coelhos abatidos aos 90 dias de idade, de acordo com os diferentes níveis de substituição da proteína bruta do farelo de soja pela proteína bruta da levedura de recuperação, seca por rotativo (LRRR) ou spray-dry (LRSD)

Table 4 - Carcass weight and carcass yield of rabbits slaughtered at 90 days of age according to the different levels of soybean meal crude protein substitution by restorative yeast crude protein dried by rotative roller (RYRR) or spray-dry (RYSD)

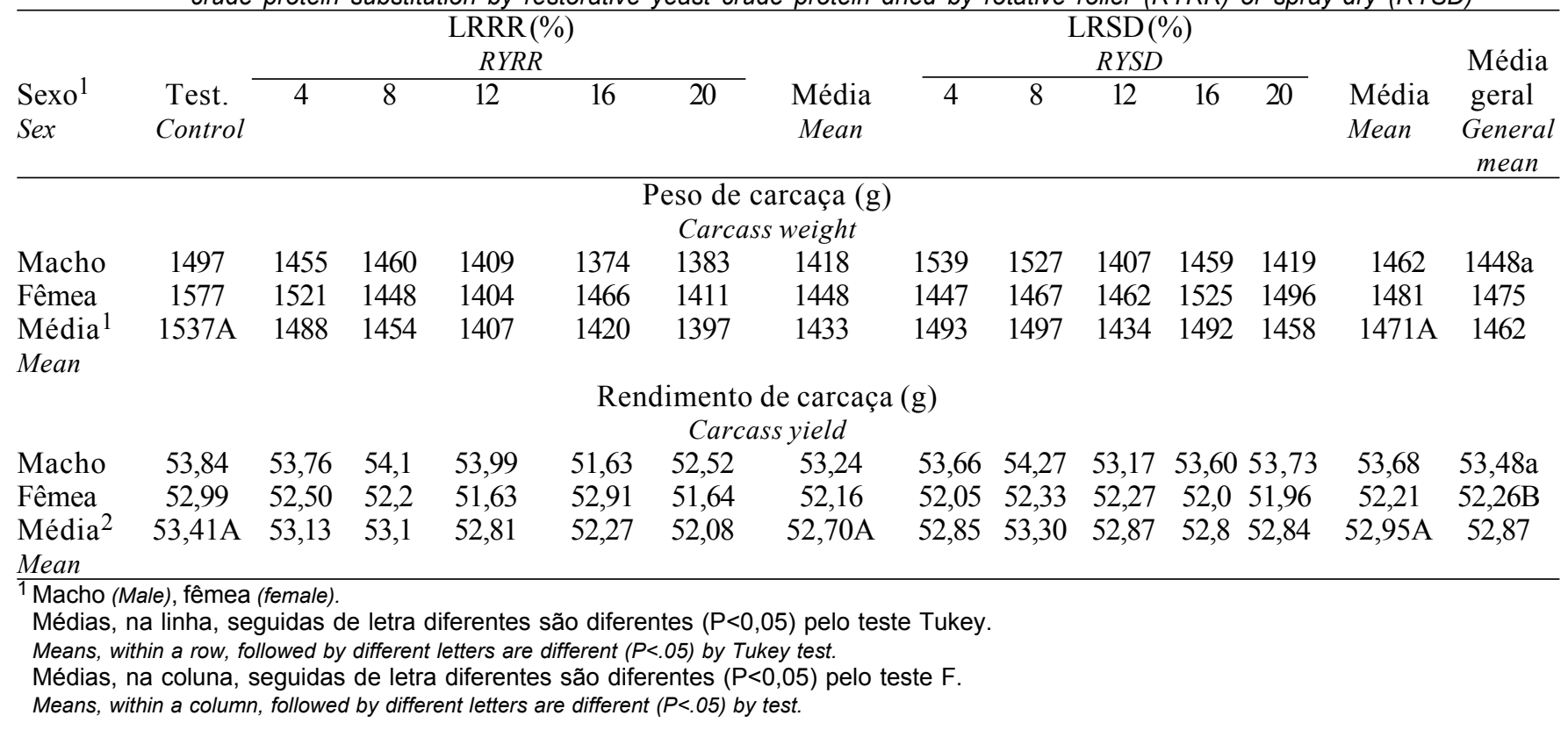


SCAPINELLO et al.

Tabela 5 - Número de mortes no período de 40 a 70, 70 a 90 e 40 a 90 dias de idade, de acordo com os diferentes níveis de substituição da proteína bruta do farelo de soja pela proteína bruta da levedura de recuperação, seca por rolo rotativo (LRRR) ou spray-dry (LRSD)

Table 5 - Number of death in the period from 40 to 70, 70 to 90 and 40 to 90 days of age according to the different levels of soybean meal crude protein substitution by restorative yeast crude protein dried by rotative roller (RYRR) or spray-dry (RYSD)

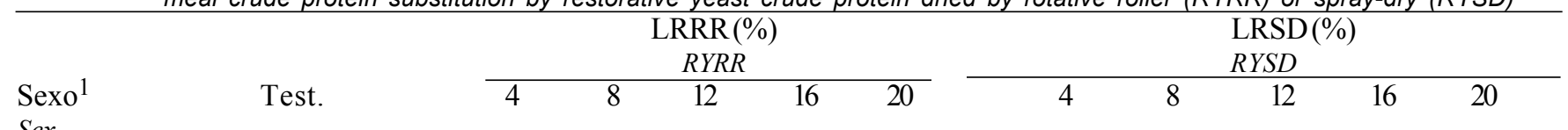

Sex

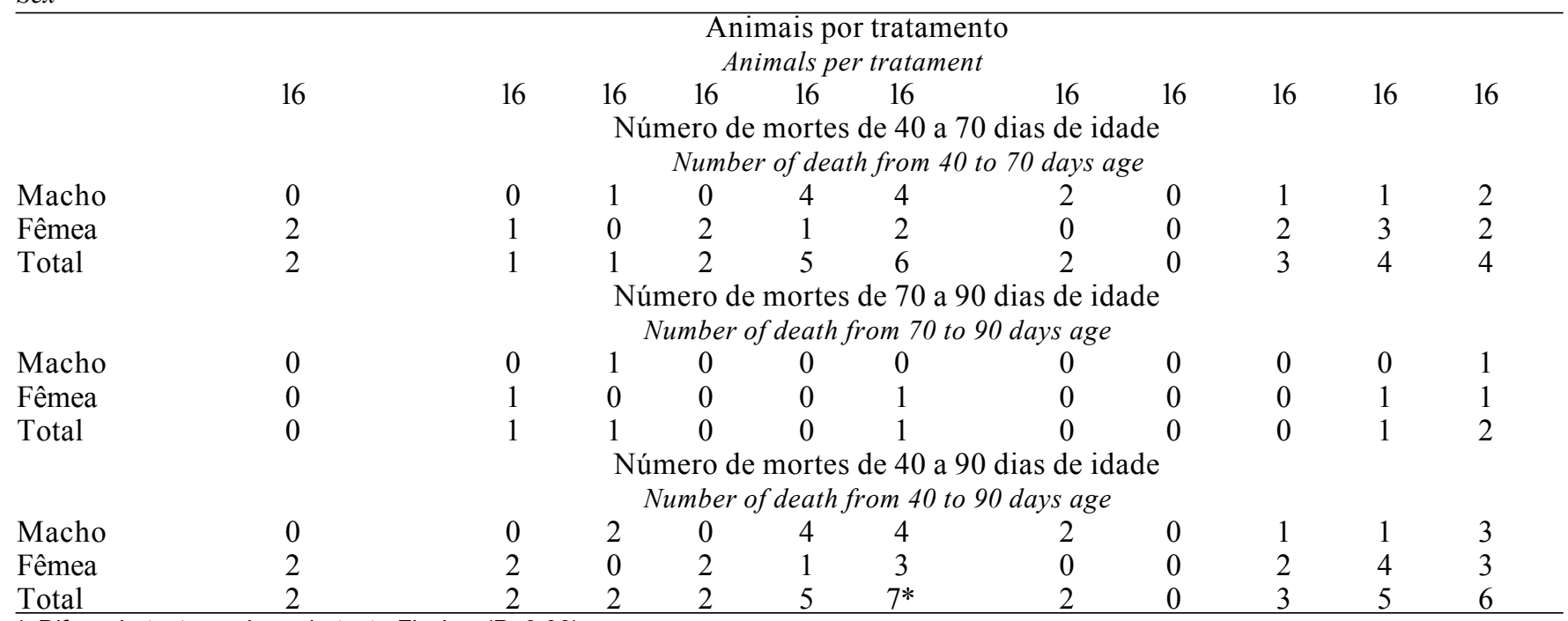

* Difere da testemunha pelo teste Fischer $(\mathrm{P}<0,06)$.

* Differ from control by Fischer test $(P<.06)$.

${ }^{1}$ Macho (Male), fêmea (female).

Tabela 6 - Custo de ração consumida/kg de ganho de peso vivo de coelhos de 40 a 70 e 40 a 90 dias de idade, de acordo com os diferentes níveis de substituição da proteína bruta do farelo de soja pela proteína brtua da levedura de recuperação (Saccharomyces sp), seca por rotativo (LRRR) ou por spray-dry (LRSD)

Table 6 - Intake diet cost/kg live weight gain of rabbits from 40 to 70 and 40 to 90 days of age according to the different levels of soybean meal crude protein substitution by restorative yeast crude protein dried by rotative roller (RYRR) or by spray-dry (RYSD)

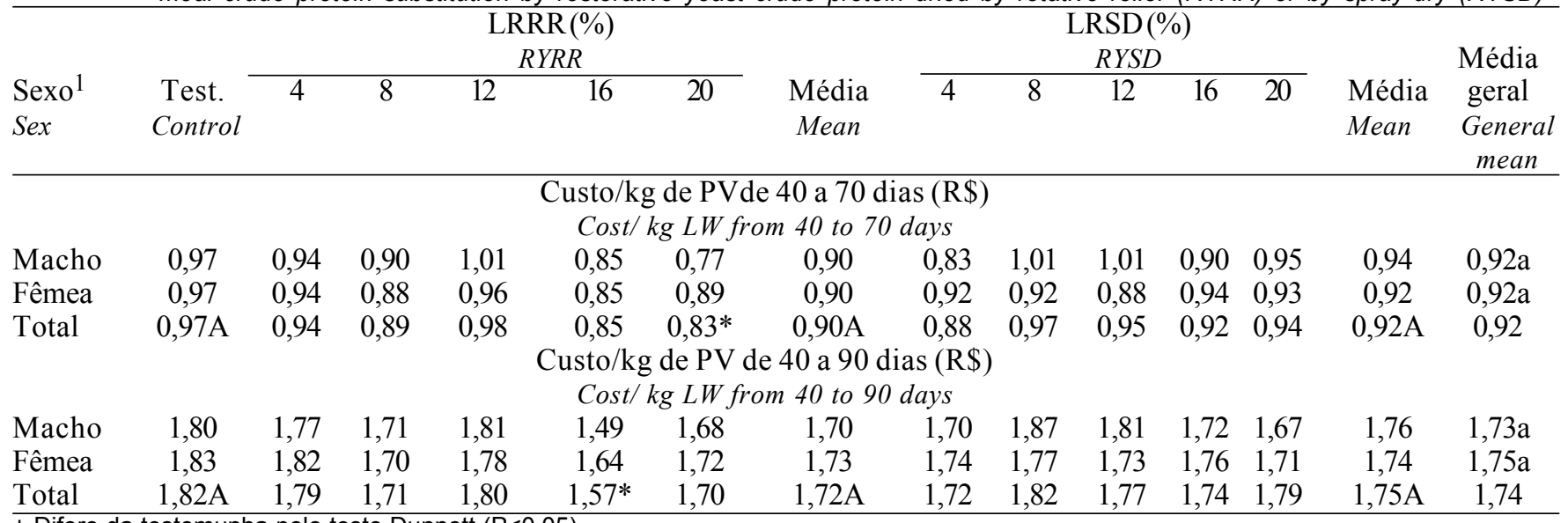

+ Difere da testemunha pelo teste Dunnett $(\mathrm{P}<0,05)$.

+ Differ from control by Dunnett test $(P<.05)$.

* Difere da testemunha pelo teste $T(P<0,05)$.

* Differ from control by $T$ test $(P<.05)$.

1 Macho (Male), fêmea (female).

2 Efeito linear para níveis de LRRR (Linear effect for RYRR levels) $\left(R^{2}=0,40\right)(\hat{Y}=0,9717194-0,00643776 \mathrm{X})$.

3 Efeito linear para níveis de LRRR (Linear effect for RYRR levels) $\left(R^{2}=0,30\right)(\hat{Y}=1,8007316-0,007591669 X)$.

Médias, na linha, seguidas de letra diferentes são diferentes $(P<0,05)$ pelo teste Tukey.

Means, within a row, followed by different letters are different $(P<.05)$ by Tukey test.

Médias, na coluna, seguidas de letras diferentes são diferentes $(P<0,05)$ pelo teste $F$.

Means, within a column, followed by different letters are different $(P<.05)$ by $F$ test. 


\section{Conclusões}

A levedura de recuperação (Saccharomyces $s p$ ) seca pelo método spray-dry substitui mais eficientemente a proteína bruta do farelo de soja que a levedura de recuperação seca em rolos rotativos até os 70 dias de idade. Entretanto, considerando-se o período total do experimento, as fontes de proteína comportaram-se de forma semelhante.

Devido à alta mortalidade observada, principalmente, no período de 40-70 dias de idade, recomendase níveis de inclusão que não sejam superiores a $15 \%$ de ambas as leveduras, substituindo $60 \%$ da proteína bruta do farelo de soja.

\section{Referências Bibliográficas}

AEC. Recomendações para nutrição. 5.ed. 1987. RHÔNE POULENC, $86 \mathrm{p}$.

BERTO, D.A. Levedura seca de destilaria de álcool de cana-deaçúcar (Saccharomyces cerevisiae) na alimentação de leitões em recria. Piracicaba, ESALQ/USP, 1985. 133p. Dissertação (Mestrado em Zootecnia) - Escola Superior de Agricultura "Luis de Queiroz"/Universidade de São Paulo, 1985.

BRENNE, T. NAESS, B. FARSTAD, L. 1974. The nutritive value, for growing pigs, of single cell protein (Candida utilis) produced from sulphit spent liquor. Acta Agric. Scand. Stockolmo, 24(1):3-6.

CARREGAL, R.D., FONSECA, T.Z. 1990. Substituição parcial e total da proteína do farelo de soja pela proteína da levedura seca em rações para coelhos em crescimento. R. Soc. Bras. Zootec., 19(3):197-200.

CARREGAL, R.D., JACOB, D.V., RESENDE, K.T. et al. 1990. Avaliação do valor nutritivo do farelo de soja e da levedura seca através da digestibilidade aparente com coelhos. In: REUNIÃO ANUAL DA SOCIEDADE BRASILEIRA DE ZOOTECNIA, 27,Campinas, 1.990. Anais... Campinas: SBZ, p.212.

FARSTAD, L. FLANTLANDSMO, T. ALMLID, T. 1980. Health and performance in growing pigs fed two sources of single cell protein in comparisom whit soybean. Acta Agric. Scand., 30(1):3-7.

FAZANO, A.R.T., ZINSLY C.F., MATTOS, W.R.S. et al. Digestibilidade e valor biológico da proteína da levedura seca (Saccharomyces spp) e do farelo de soja para coelhos. In: REUNIÃO ANUAL DA SOCIEDADE BRASILEIRA DE ZOOTECNIA, 26, Porto Alegre, 1989. Anais... Porto Alegre: SBZ, p.229, 1989.

HANSSEN, J. T. FARSTAD, L. 1980. Effects of feeding large amounts of "pruteen" and "toprina"on some biological parameters in growing finishing pigs. Acta Agric. Scand., 30(1):74-80.

LANDELL, L.C., KRONKA, R.N., THOMAZ, M.C. et al. 1994. Utilização da levedura de centrifugação da vinhaça (Saccharomyces cerevisiae) como fonte protéica para leitões na fase inicial (10 a $30 \mathrm{~kg}$ PV). R. Soc. Bras. Zootec., 23(2):283-291.

LIMA,G. J. M. M. Uso de levedura seca (Saccharomyces cerevisiae) de destilarias de álcool de cana de açúcar na alimentação de matrizes suínas em gestação e lactação. Piracicaba: ESALQ/USP. 1983, 139p. Dissertação (Mestrado em Zootecnia) - Escola Superior de Agricultura "Luis de Queiroz"/Universidade de São Paulo, 1983.

MIYADA, V.S. A levedura seca na alimentação de suínos: Estudos adicionais sobre o seu valor protéico e vitamínico. Piracicaba, SP: ESALQ, 1987. 139p. Tese (Doutorado em Zootecnia) - Escola Superior de Agricultura "Luiz de Queiroz"/ Universidade de São Paulo, 1987.

MIYADA, V.S., LAVORENTI, A. 1979. Uso de levedura seca (Saccharomyces cerevisiae) de destilaria de álcool de canade-açúcar na alimentação de suínas em crescimento e acabamento. R. Soc. Bras. Zootec., 8(3):497-515.

MIYADA, V.S., LAVORENTI, A., PACKER, L.U. 1992. A levedura seca como ingrediente de rações fareladas ou peletizadas de leitões em recria. R. Soc. Bras. Zootec., 21(3):439-446.

MOREIRA, J.R.A. Uso da levedura seca (Saccharomyces cerevisiae) de destilarias de álcool de cana-de-açúcar em rações isocalóricas para suínos em crescimento e acabamento. Piracicaba: ESALQ/USP. 1984, 107p. Dissertação (Mestrado em Zootecnia) - Escola Superior de Agricultura "Luis de Queiroz"/Universidade de São Paulo, 1984.

MOREIRA, I. MURAKAMI, A.E., SCAPINELLO,C. 1994. Utilização da levedura seca (Saccharomyces spp) na alimentação de suínos na fase de crescimento. R. Unimar, 16:111121 (suplemento).

NUNES, J.R.V. Uso de levedura de cana (Saccharomyces cerevisiae) na alimentação inicial de leitões In: REUNIÃO ANUAL DA SOCIEDADE BRASILEIRA DE ZOOTECNIA, 25, 1988, Viçosa. Anais... Viçosa: SBZ, p.18, 1988.

SALGADO, J.M. Alguns fatores que afetam a qualidade de concentrado proteico obtido em destilaria de álcool. Piracicaba: ESALQ/USP. 1976, 50p. Dissertação (Mestrado em Zootecnia) - Escola Superior de Agricultura "Luis de Queiroz"/ Universidade de São Paulo, 1976.

SCAPINELLO, C. Niveis de proteina bruta e de energia digestivel e exigências de lisina e de metionina + cistina, para coelhos da raça nova zelândia branco, em crescimento. Viçosa, MG: UFV, 1993. 215p. Tese (Doutorado em Zootecnia) -Universidade Federal de Viçosa, 1993.

SCAPINELLO, C., FURLAN, A.C. MOREIRA, I. et al. 1996. Utilização da levedura de recuperação (Saccharomyces sp), seca pelo método "spray-dry" para coelhos em crescimento. R. Unimar, 18(3):587-598.

TEGBE, S.B. ZIMMERMAN. D. R. 1977. Evolution of yeast single all protein in pig diets. J. Anim. Sci., 45(6):1309-1315.

Recebido em: 09/02/98

Aceito em: 25/09/98 